\title{
Cognitive evaluation following NMR imaging of the brain
}

\author{
JAO BESSON, E ILJON FOREMAN, LM EASTWOOD, FW SMITH, \\ GW ASHCROFT \\ From the Department of Mental Health, Clinical Research Centre, Royal Cornhill Hospital, Aberdeen, UK
}

SUMMARY Nuclear magnetic resonance imaging of the brain will soon be a standard neuroradiological investigation. Previous work has indicated that this is a safe procedure. Tests which measure various aspects of cognition were performed on volunteer subjects before and after (medium and short term) NMR brain imaging and indicate that deterioration did not occur.

The introduction of new imaging techniques bring with it concern regarding its potential hazards. The exposure of the central nervous system of primates to large static magnetic fields $(5 \mathrm{~T}$ or $50000 \mathrm{G})$ have produced measurable physiological and neurological change. ${ }^{1}$ These fields are far in excess of those used in clinical nuclear magnetic resonance (NMR) studies. Thomas and Morris ${ }^{2}$ have failed to demonstrate any mutagenic or lethal effects of fields of NMR of $1 \mathrm{~T}$ on bacteria and Cooke and Morris ${ }^{3}$ failed to detect any morphological or chromatogical change in human lymphocytes. Mastaglia and $\mathrm{Cala}^{4}$ implied the possibility of adverse effects of NMR on patients with organic brain disease, in particular in terms of abnormal tissue excitation, an observation not supported by any tangible data and rejected by the large clinical experience of Smith. ${ }^{5}$ Furthermore, subjects who had EEGs before and within two hours of completion of NMR exposure showed no change on visual examination of the EEG records.

The three possible direct sources of biological hazard in NMR imaging are static magnetic field, varying magnetic fields and radio frequency fields. Evidence of hazard is sparse and predominantly negative. In the UK the National Radiological Protection Board (NRPB) has drawn up a set of safety guidelines ${ }^{6}$ suggesting upper limits for the various fields, and contraindications for imaging, such as a history of epilepsy or cardiac disease. These are based largely on caution rather than on proven complications.

Address for reprint requests: Dr JAO Besson, Royal Cornhill Hospital, Cornhill Rd, Aberdeen, AB9 2ZH, UK

Received 5 May 1983 and in revised form 30 September 1983 Accepted 8 October 1983
Static magnetic fields used in clinical NMR imaging vary from about $0.04 \mathrm{~T}$ to $1.5 \mathrm{~T}$. The NRPB guidelines currently suggest an upper limit of $2.5 \mathrm{~T}$ for the static field. Biological hazards are most likely to arise by the creation of an electric potential which might arise where there is flowing material, for example, blood vessels, and to a lesser degree will occur across individual cell membranes. At the field strength used in this study $(0.04 \mathrm{~T})^{78}$ this is probably unlikely to occur. The highest potential develops across the aorta, the point of maximum flow, and is about $1 \mathrm{mV}$. Across individual cells this is likely to be even smaller. Moreover, in order to achieve depolarisation a potential difference across the cell of about $40 \mathrm{mV}$ is required.

Switched magnetic fields can set up eddy currents in soft tissue. The effects of these in vivo are unknown. These may arise from field gradient coils at gradient pulsing and in the main magnet at switch-on or switch-off. In the latter case rate of change is determined by the time constant of magnetic inductance and resistance. In the study described, the imager used a $0.04 \mathrm{~T}$ magnet at a time constant of 0.3 $\mathrm{s}$ which limits rate of field change to $0 \cdot 12 \mathrm{~T} / \mathrm{s}$. This is very small by comparison with those of super conducting systems, for example. The field changes due to the gradients are limited to $1 \mathrm{~T} / \mathrm{s}$ in the head and one only applied for about $2 \mathrm{~ms} / \mathrm{s}$ in pulse sequences used in this study. ${ }^{9}$

The main effect of exposure to radio frequency fields is probably the consequence of temperature increase. In the imager currently used the peak RF field is $40 \mu \mathrm{T}$ at $1.7 \mathrm{MHz}$ applied for $10 \mathrm{~m} / \mathrm{s}$ every two seconds and the time averaged power deposition is small compared with the basal metabolic rate. This effect is therefore small. 
Table 1 (a) The reports of WAIS, WMS and Word Fluency Tests before and after exposure to NMR imaging

\begin{tabular}{|c|c|c|c|c|c|c|c|c|c|c|}
\hline \multirow[t]{3}{*}{ Subjects } & \multicolumn{10}{|l|}{ WAIS } \\
\hline & \multicolumn{2}{|c|}{ Verbal IQ } & \multicolumn{2}{|c|}{ Performance $I Q$} & \multicolumn{2}{|c|}{ Full-scale IQ } & \multicolumn{2}{|l|}{$W M S$} & \multicolumn{2}{|c|}{ Word fuency } \\
\hline & Before & After & Before & After & Before & After & Before & After & Before & After \\
\hline $\begin{array}{l}1 \\
2 \\
3 \\
4 \\
5 \\
6 \\
7\end{array}$ & $\begin{array}{c}130 \\
136 \\
114 \\
120 \\
100 \\
98 \\
127 \\
*_{t}=-3 . \\
\mathrm{p}=0.0\end{array}$ & $\begin{array}{l}129 \\
137 \\
122 \\
128 \\
109 \\
107 \\
134\end{array}$ & $\begin{array}{l}122 \\
135 \\
110 \\
119 \\
99 \\
106 \\
140 \\
t=-2 \\
\text { NS }\end{array}$ & $\begin{array}{l}118 \\
143 \\
122 \\
128 \\
105 \\
105 \\
141\end{array}$ & $\begin{array}{l}128 \\
138 \\
113 \\
121 \\
99 \\
102 \\
134 \\
\mathrm{t}_{2}=-3 \\
\mathrm{p}=0.0\end{array}$ & $\begin{array}{l}126 \\
142 \\
124 \\
130 \\
108 \\
106 \\
139\end{array}$ & $\begin{array}{l}135 \\
143 \\
120 \\
114 \\
101 \\
101 \\
143 \\
\mathrm{t}=0.09 \\
\text { NS }\end{array}$ & $\begin{array}{r}129 \\
143 \\
122 \\
116 \\
124 \\
96 \\
124\end{array}$ & $\begin{array}{l}19 \\
16 \\
10 \\
13 \\
13 \\
11 \\
22 \\
\mathrm{t}=-1 \\
\text { NS }\end{array}$ & $\begin{array}{r}21 \\
17 \\
11 \\
14 \\
20 \\
9 \\
24\end{array}$ \\
\hline
\end{tabular}

*Paired $t$-tests have been used throughout. Negative ' $t$ ' values indicate improvement

Details of subtest scores are available from the authors

Table 1(b) The reports of Stroop test before and after exposure to NMR imaging

\begin{tabular}{|c|c|c|c|c|c|c|c|c|c|c|c|c|}
\hline \multirow[t]{3}{*}{ Subjects } & \multicolumn{6}{|l|}{ Words } & \multicolumn{6}{|l|}{ Colours } \\
\hline & \multicolumn{2}{|c|}{ Total time $(s)$} & \multicolumn{2}{|c|}{ Corrected errors } & \multicolumn{2}{|c|}{ Uncorrected errors } & \multicolumn{2}{|c|}{ Total time $(s)$} & \multicolumn{2}{|c|}{ Corrected errors } & \multicolumn{2}{|c|}{ Uncorrected errors } \\
\hline & Before & After & Before & After & Before & After & Before & After & Before & After & Before & After \\
\hline $\begin{array}{l}1 \\
2 \\
3 \\
4 \\
5 \\
6 \\
7\end{array}$ & $\begin{array}{l}50 \\
40 \\
42 \\
36 \\
44 \\
42 \\
46 \\
t=-1 . \\
\text { NS }\end{array}$ & $\begin{array}{l}52 \\
41 \\
52 \\
32 \\
47 \\
45 \\
52\end{array}$ & $\begin{array}{l}0 \\
0 \\
2 \\
0 \\
0 \\
0 \\
0\end{array}$ & $\begin{array}{l}0 \\
0 \\
2 \\
0 \\
0 \\
0 \\
0\end{array}$ & $\begin{array}{l}0 \\
0 \\
0 \\
0 \\
0 \\
0 \\
0\end{array}$ & $\begin{array}{l}1 \\
0 \\
0 \\
0 \\
0 \\
0 \\
0\end{array}$ & $\begin{array}{l}112 \\
162 \\
107 \\
95 \\
135 \\
117 \\
110 \\
\mathrm{t}=1 \cdot 79 \\
\text { NS }\end{array}$ & $\begin{array}{r}128 \\
108 \\
93 \\
91 \\
118 \\
104 \\
97\end{array}$ & $\begin{array}{l}0 \\
2 \\
0 \\
1 \\
0 \\
2 \\
2\end{array}$ & $\begin{array}{l}4 \\
0 \\
3 \\
0 \\
0 \\
3 \\
1\end{array}$ & $\begin{array}{l}3 \\
0 \\
2 \\
0 \\
0 \\
0 \\
0\end{array}$ & $\begin{array}{l}0 \\
0 \\
0 \\
0 \\
0 \\
0 \\
0\end{array}$ \\
\hline
\end{tabular}

In this study we examined two possible consequences of exposure of the brain to these magnetic field influences during imaging. These were the acute short-term effects of exposure and the medium-term chronic effects.

\section{Method}

Seven normal healthy volunteers, ages ranging from 26 years to 51 years, were tested using a battery of psychometric tests. Each subject had NMR brain imaging with total exposure of ten minutes involving five horizontal sections through the cerebral hemispheres. This procedure was repeated at a mean of four months after the first series of imaging (range 2-6 months) and was followed 1-5 days after by a repetition of the battery of psychometric tests carried out before exposure. The time interval between first and second psychometric tests was sufficiently long to minimise, though not entirely abolish, the effect of practice on performance of the tests.

It is generally accepted that cognitive functions are best assessed using many faceted measuring instruments. The most widely used test of mental ability-the Wechsler Adult Intelligence Scale-is compiled of a variety of tests which fall into two categories, the "Verbal" and "Performance" categories. ${ }^{10}$ Memory functions were tested using the Wechsler Memory Scale. This test is available in two forms with differing content reducing the influence of practice on performance.

The Word Fluency Test ${ }^{11}$ has been shown to be highly discriminant for brain damage, even for patients of high intelligence, if difficult letters are given. Furthermore, it has been shown that practice and fatigue effects can be eliminated by modification of the number of letters administered. These findings were taken into account in the planning of this test.

The Stroop-Colour-Word Test ${ }^{12}$ consists of a sequence of names of colours printed in incongruously coloured ink. The subject is asked: (1) to name the colour in which the words are printed: (2) read the printed words. The two conditions require different aspects of the stimulus to be ignored. The Stroop test can be used to compare two different cognitive processes, that is reading and naming, and this would isolate abnormal function of the left (verbal) hemisphere, particularly the frontal lobe.

\section{Results}

In only one of the tests was there any statistically significant change in performance before and after exposure to the magnetic field. This occurred in the verbal IQ $(p=0.01)$ and full scale IQ $(p=0.05)$ of the WAIS. This change was in the direction of improvement and is most likely due to the effect of practice.

\section{Discussion}

The failure to detect cognitive deterioration on retesting would indicate that no change as measured by these tests occurs as an immediate result of exposure 
or as a delayed result of exposure to the magnetic field. The Wechsler Memory Scale and the Word Fluency Test were available in two different forms and so the practice effect was minimised. The colour and word sequence in the Stroop are random, making the sequences difficult to recall after a lengthy period when this test is applied on the second occasion. Recall of some items on the WAIS may have contributed to the improved performance of most subjects on second presentation. These results, although restricted in their scope, nevertheless support the existing negative findings of adverse effects of magnetic field strengths used in clinical NMR imaging.

\section{References}

${ }^{1}$ Barnothy MF. Biological Effects of Magnetic Fields. New York: Plenum, 1964.

${ }^{2}$ Thomas A, Morris PG. Effects of NMR exposure on living organisms (i) Microbiol assay. Br J Radiology 1981;54:615.
${ }^{3}$ Cooke P, Morris PG. Effects of NMR exposure on living organisms (ii) A genetic study of human lymphocytes. Br J Radiology 1981;54:622.

${ }^{4}$ Mastaglia FL, Cala LA. Nuclear magnetic resonance imaging and computerised tomography in multiple sclerosis. Lancet 1982;1:850.

${ }^{5}$ Smith FW. Safety of NMR imaging. Lancet 1982;1:974.

${ }^{6}$ National Radiological Protection Board-Exposure to NMR Clinical Imaging. Didcot, Oxon: NRPB, 1980.

${ }^{7}$ Hutchison JMS, Edelstein WA, Johnson G. A whole body NMR imaging machine. $J$ Phys E; Sci Instrum 1982;15:74.

${ }^{8}$ Johnson G, Hutchison JMS, Eastwood LM. Instrumentation for NMR spin-warp imaging. J Phys $E ; S c i$ Instrum 1982;15:74.

${ }^{9}$ Edelstein WA, Hutchison JMS, Johnson G, Redpath T. Spin-warp NMR imaging and application to human whole body imaging. Phys Med Biol 1980;25:751-6.

${ }^{10}$ Lezak MD. Neuropsychological Assessment. New York: Oxford University Press, 1976.

${ }^{11}$ Borkowski JG, Benton AL, Spreen O. Word Fluency and Brain Damage. Neuropsychologia Vol. 5,1967;135:40.

12 Jensen AR, Rohwer WD. The Stroop Color-Word Test: A Review. Acta Psychologica 1966;25:36-93. 